УДК 550.36, 553.065

\title{
ПОВЫШЕНИЕ ЭНЕРГЕТИЧЕСКОЙ ЭФФЕКТИВНОСТИ БИНАРНОЙ ГЕОЭС (НА ПРИМЕРЕ КУМУХСКОГО МЕСТОРОЖДЕНИЯ)
}

\author{
Джаватов Джават Курбанович 1,2 \\ Азизов Амир Азизович², \\ azizov_amir@mail.ru \\ 1 Дагестанский государственный университет, \\ Россия, 367000, Махачкала, ул. Гаджиева, 43 а. \\ 2 Институт проблем геотермии и возобновляемой энергетики - филиал Объединенного института высоких темпера- \\ тур Российской академии наук, \\ Россия, 367030, Махачкала, пр. Имама Шамиля, 39 а.
}

\begin{abstract}
Актуальность исследования обусловлена необходимостью расширения топливно-энергетической и минерально-сырьевой базы путем освоения возобновляемых высокопотенциальных минерализованных ресурсов месторождений термальных вод. Однако эксплуатация таких месторождений затруднена высокой степенью минерализации природных рассолов. Использование бинарных геотермальных электростанций, реализующих термодинамический цикл Ренкина для утилизации тепловой энергии, позволяет решить эту проблему и получить относительно дешевую электрическую энергию. Возникает необходимость поиска и оценки методов повышения энергоэффекктивности термодинамических циклов, реализуемых при разработке одного из перспективных месторождений термальных вод Дагестана - Кумухское. Положительная оценка перспектив освоения геотермальных ресурсов месторождения показывает значительный потенциал для улучшения экономической структуры региона.

Цель: оценить энергоэффрективность бинарной геотермальной электростанции, в основе работы которой лежит органический цикл Ренкина в докритическом и сверхкритическом циклах и в разных режимах закачки отработанного теплоносителя для Кумухского месторождения термальных вод; показать перспективность и эффрективность комплексного освоения геотермальных ресурсов месторождения

Объект: геотермальные системы для электроэнергетического освоения высокопотенциальных минерализованных термальных вод месторождения.

Методы исследования основаны на использовании данных геологоразведочных, гидротермальных и геохимических исследований по Кумухскому месторождению термальных вод, методов математического моделирования и оптимизации.

Результаты. На примере конкретного месторождения термальных вод проведена оптимизация технологических параметров первичного контура геотермальной электростанции, оценена ее энергоэффрективность в докритическом и сверхкритическом органических циклах Ренкина с низкокипящим вторичным теплоносителем. Показано, что утилизация низкопотенциальной энергии рассолов на теплонасосных установках позволяет улучшить эфффективность энергетических циклов на месторождении. Проведенный анализ показывает, что создание комплексных технологий освоения высокопотенциальных минерализованных геотермальных ресурсов месторождения позволит существенно улучшить экономическую структуру региона.
\end{abstract}

\section{Ключевые слова:}

Месторождение термальных вод, геотермальная циркуляционная система,

бинарные геотермальные электростанции, докритический и сверхкритический циклы Ренкина,

низкокипящее рабочее вещество, оптимизация, низкопотенциальное тепло, теплонасоснье установки.

\section{Введение}

Геотермальная энергия как один из видов возобновляемых альтернативных ресурсов имеет практически неиссякаемый ресурс тепловой и электрической энергии [1-6]. Электроэнергетическое освоение высокотемпературных термальных вод (ТВ) с температурой более $100{ }^{\circ} \mathrm{C}$ позволяет получать экологически чистую, относительно недорогую электрическую энергию. А освоение низкопотенциальной энергии TВ с использованием теплонасосных установок - это и экономия традиционных энергоресурсов, и защита окружающей среды [7].

Высокая степень минерализации природных рассолов (до 200 г/л) и тепловой потенциал теплоносителей, достигающий значений более $150{ }^{\circ} \mathrm{C}$ [8], ряда перспективных месторождений ТВ на Севере Дагестана делают электроэнергетическое освоение таких ресурсов целесообразным только с использованием технологии двухконтурных, бинарных геотермальных электростанций (ГеоЭС) [9-13]. Использование ГеоЭС такого типа значительно увеличивает перспективы геотермальной энергетики, позволяя получить сравнительно дешевую по стоимости (в среднем на 30 \%) электроэнергию, а также расширяет число регионов, перспективных с точки зрения использования геотермальной энергии. Сегодня разработаны и успешно эксплуатируются десятки бинарных ГеоЭС во всем мире с разнообразными технологическими схемами. В России имеются лишь единичные примеры такого использования ТВ [9].

Имеющиеся большие запасы геотермальных ресурсов с температурой более $100{ }^{\circ} \mathrm{C}$ делают актуальной проблему повышения эффективности бинарной ГеоЭС, которая во многом зависит от параметров пласта, термодинамических характеристик теплоносителя, от выбора технологических параметров гео- 
термальной циркуляционной системы (ГЦС), составляющей основу ГеоЭС, и от вида термодинамического цикла вторичного контура в паротурбинной установке (ПТУ).

Несмотря на очевидные преимущества, разработанные технологические схемы бинарных ГеоЭС имеют резервы совершенствования. Так, повышения эффективности ГеоЭС можно добиться разными способами, например, выбором соответствующего рабочего тела для вторичного контура и оптимизацией термодинамического цикла в ПТУ, применением турбин и циклов, работающих на водоаммиачной смеси, оптимизацией технологических параметров первичного контура, выбором соответствующего термодинамического цикла Ренкина (докритический или сверхкритический) во вторичном контуре и др. Значительного экономического эффекта от использования геотермальной энергии для производства электроэнергии можно добиться использованием отработанного в ГеоЭС низкопотенциального теплоносителя с помощью теплонасосных установок для различных целей (отопление, горячее водоснабжение, сельское хозяйство и другие) при разных значениях температуры закачиваемого теплоносителя [14]. Кроме того, значительная температурная зависимость вязкости теплоносителя и, соответственно, потерь давления в цикле ГЦС делают необходимым проведение сравнительной оценки эффективности эксплуатации ГеоЭС при различных значениях температуры отработанной $\mathrm{TB}$, закачиваемой обратно в пласт, для выбора наиболее оптимального режима закачки. Такая оценка эффективности бинарной ГеоЭС в докритическом и сверхкритическом циклах Ренкина при различных температурах закачиваемого теплоносителя на устье нагнетательной скважины до настоящего времени не проводилась.

Цель данной работы - показать перспективы освоения ресурсов ТВ и возможности повышения эффективности бинарной ГеоЭС (на примере Кумухского месторождения ТВ) на основе оптимизации технологических параметров первичного контура ГЦС и выбора соответствующего термодинамического цикла в ПТУ при различных температурах закачиваемого теплоносителя, оценить возможный экономический эффект.

\section{Основная часть}

Одним из перспективных в электроэнергетическом освоении высокотемпературных геотермальных рассолов является месторождение Кумухское, расположенное на Севере Дагестана. Основные характеристики месторождения [8] позволяют рассматривать его как перспективное с энергетической точки зрения. Природные рассолы месторождения также содержат химические компоненты - магнезия жженная, карбонат кальция, карбонат лития и поваренная соль [8].

Из-за высокой минерализованности природных рассолов месторождения их электроэнергетическое освоение обусловлено использованием технологии на основе бинарных ГеоЭС. Просчитаем различные варианты проектирования бинарной ГеоЭС на Кумух- ском месторождении и проведем соответствующую оценку их эффективности.

Рассматривается бинарная ГеоЭС с циркулирующей ТВ в первичном контуре и с низкокипящим вторичным теплоносителем - во вторичном. Полагаем, что в ПТУ реализуется экономичный цикл Ренкина. В России и за рубежом ведутся исследования по проблеме поиска рабочих тел нового поколения, мы в качестве вторичного теплоносителя рассмотрим наиболее перспективный рабочий агент - изобутан, который обладает рядом преимуществ (лучшие теплофизические свойства, совместимость с маслами, не вызывает коррозии оборудования энергоустановок, невысокая стоимость и экологическая безвредность) [10].

Главной целью строительства ГеоЭС является получение максимальной полезной мощности с минимизацией капитальных затрат на ее создание. Капитальные затраты составляют основную статью расходов создания ГеоЭС, и оптимизация параметров первичного контура ГЦС с учетом этих затрат позволит повысить эффективность ГеоЭС, снизить себестоимость получаемой энергии.

За критерий оптимальности рассмотрим функционал удельных капитальных затрат, определяемый по формуле [15]:

$$
F=S / N_{n},
$$

где $S$ - капитальные затраты в строительство ГЦС и наземной коммуникации, отн. ед.; $N_{n}$ - полезная мощность ГеоЭС, МВт.

Для сравнительной оценки рассмотрим два вида термодинамических цикла ПТУ, в основе работы которых лежит цикл Ренкина - докритический или сверхкритический [16], и проведем оптимизацию и оценку эффективности ГеоЭС в каждом из них.

Анализ эффективности ГеоЭС проведем с учетом значительных энергозатрат на обратную закачку отработанного теплоносителя в ГЦС $[17,18]$.

Технологическую основу ГеоЭС составляет циркуляционная система с добычной и нагнетательной скважинами. Вид термодинамического цикла, реализуемого в ПТУ ГеоЭС, определяет температуру теплоносителя на устье нагнетательной скважины.

Температура теплоносителя на забое нагнетательной скважины ГЦС $T_{3}$ зависит от температуры теплоносителя на устье $T_{y}$ от дебита нагнетательной скважины $G$ времени эксплуатации ГЦС $t$ и от геологических характеристик окружающих пород.

Эта зависимость достаточно хорошо описывается формулой Намиота [19]:

$$
\begin{gathered}
T_{3}(t)=\Theta_{0}+\frac{\Gamma}{\beta_{0}}\left(\beta_{0} H-1\right)+\left(T_{\mathrm{y}}-\Theta_{0}+\frac{\Gamma}{\beta_{0}}\right) \times \\
\times \exp \left(-\beta_{0} H\right), \\
\beta_{0}=\frac{2 \pi \lambda_{\text {оп }}}{Q C_{\mathrm{B}} \rho_{\mathrm{B}} \ln \left(\frac{r(t)}{r_{\mathrm{c}}}\right)}, \\
r(t)=2 \sqrt{x_{\text {оп }} t},
\end{gathered}
$$


где $\Theta_{0}$ - температура нейтрального слоя, ${ }^{\circ} \mathrm{C} ; \Gamma$ - геотермический градиент, K/м; $x_{\text {оп }}$ - температуропроводность окружающих пород, $\mathrm{m}^{2} / \mathrm{c} ; H$ - глубина скважины, м; $\lambda_{\text {оп }}$ - теплопроводность окружающих пород, $\mathrm{Bт} / \mathrm{M} \cdot \mathrm{K} ; Q-$ объемный дебит скважины, $\mathrm{m}^{3} / \mathrm{c} ; \rho_{\mathrm{B}}, C_{\text {в }}$ плотность и теплоемкость воды, соответственно, кг $/ \mathrm{M}^{3}$, КДж/(кг К $) ; r_{\mathrm{c}}$ - радиус скважины, м; $t$ - время эксплуатации ГЦС, с.

От температуры теплоносителя на забое нагнетательной скважины зависит важная характеристика ГЦС - вязкость, величина которой существенно влияет на фильтрационные потери давления в пласте, а значит и на полезную мощность ГеоЭС [17].
Проведем оптимизацию технологических параметров первичного контура ГеоЭС - дебит системы, диаметры скважин, расстояние между скважинами, обеспечивающие минимум функционала (1). Соответствующие формулы для расчета основных технологических параметров приведены в работах $[16,20]$.

\section{Результаты исследования и обсуждение}

На рис. 1 для Кумухского месторождения ТВ показана зависимость температуры теплоносителя на забое нагнетательной скважины $T_{3}$ и вязкости $\mu$ от дебита ГЦС $G$ при устьевой температуре $T_{H}=42{ }^{\circ} \mathrm{C}$ по формуле (2).

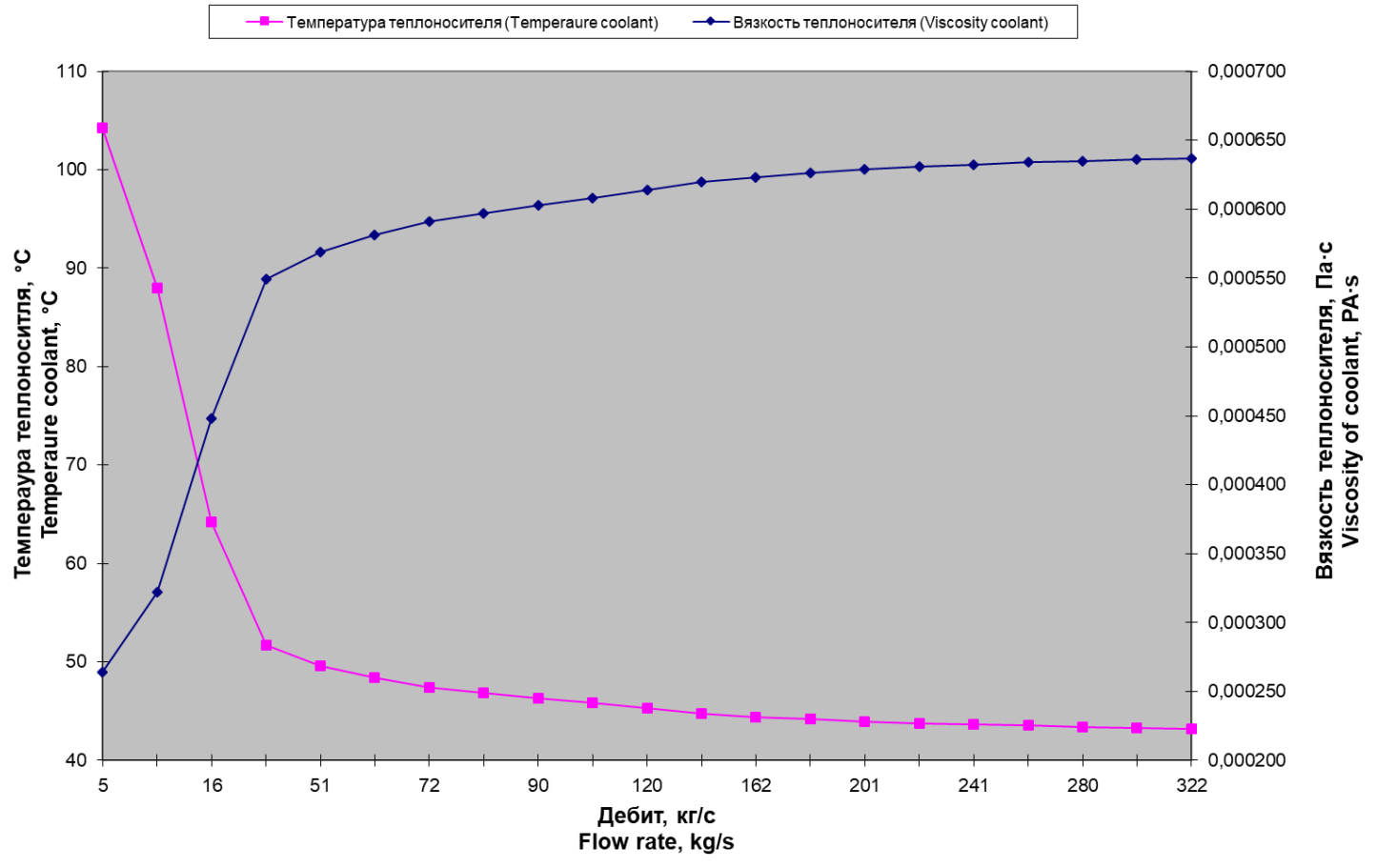

Рис. 1. Изменение температуры и вязкости теплоносителя

Fig. 1. Change of temperature and viscosity of coolant

Анализ приведенных данных показывает, что прогрев закачиваемого теплоносителя от устья до забоя относительно заметен для значений дебита до 40 кг/с (более $10{ }^{\circ} \mathrm{C}$ ), для дебитов больше этого значения температуру теплоносителя на устье и забое нагнетательной скважины можно брать одинаковой.

Для этих же дебитов изменение значения вязкости составляет более чем два раза.

Для изобутана, как низкокипящего рабочего агента, при реализации предполагаемой технологической схемы ГеоЭС, при температуре теплоносителя в первичном контуре $T_{\mathrm{T}}=180^{\circ} \mathrm{C}$, значение удельной полезной мощности ПТУ $N_{\ni}$ (кВТ) в докритическом цикле составит $N_{\ni}=76,6$ кВт и сверхкритическом $-N_{\ni}=101,1$ кВт [16]. Температура отработанной термальной воды, закачиваемой обратно в пласт, при этом составляет $T_{\mathrm{H}}=55{ }^{\circ} \mathrm{C}$ и $T_{\mathrm{H}}=42{ }^{\circ} \mathrm{C}$, соответственно.

Полезная мощность турбины в сверхкритическом цикле на 32 \% выше, по сравнению с докритическим, a температура отработанной термальной воды $T_{\mathrm{H}}$ нагнетаемой обратно в пласт, в докритическом цикле выше, чем в сверхкритическом цикле, на $13{ }^{\circ} \mathrm{C}$.

При этом изменение вязкости ТВ (увеличение) для температур $T_{\mathrm{H}}=55{ }^{\circ} \mathrm{C}$ и $T_{\mathrm{H}}=42{ }^{\circ} \mathrm{C}$ составляет более $20 \%$, что соответственно ведет к увеличению фильтрационных потерь давления в пласте в сверхкритическом цикле.

Результаты расчетов основных технологических параметров ГеоЭС для Кумухского месторождения ТВ при различных значениях диаметров скважин ГЦС приведены в табл. 1. Соответствующие формулы для расчета основных технологических параметров приведены в работах $[16,20]$.

Результаты оптимизации технологических параметров ГеоЭС приведены в табл. 2.

Отработанная термальная вода как в докритическом, так и в сверхкритическом циклах имеет еще достаточно большой тепловой потенциал, который можно утилизировать, но эта вода практически не годится для нужд теплоснабжения и горячего водоснабжения из-за невысокой температуры. 
Таблица 1. Параметры ГеоЭС в докритическом и сверхкритическом циклах Ренкина и оптимальные значения этих параметров

Table 1. GeoES parameters in subcritical and supercritical Rankine cycles and optimal values of these parameters

\begin{tabular}{|c|c|c|c|c|c|c|c|c|}
\hline \multirow[b]{2}{*}{$\begin{array}{c}\text { Диаметр добыч- } \\
\text { ной и нагнета- } \\
\text { тельной скважин } \\
\left(\mathrm{d}_{\mathrm{H}}=\mathrm{d}_{\bar{z}}\right), \mathrm{M} \\
\text { Diameter of } \\
\text { production and } \\
\text { injection wells, m }\end{array}$} & \multicolumn{3}{|c|}{$\begin{array}{l}\text { Докритический цикл Ренкина } \\
\text { Subcritical cycle Rankine }\end{array}$} & \multicolumn{3}{|c|}{$\begin{array}{c}\text { Сверхкритический цикл Ренкина } \\
\text { Supercritical cycle Rankine }\end{array}$} & \multirow{2}{*}{ 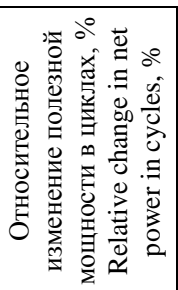 } & \multirow{2}{*}{ 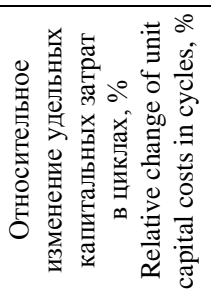 } \\
\hline & 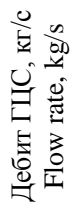 & 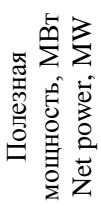 & 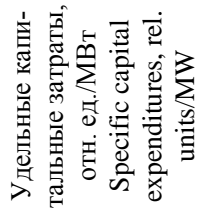 & 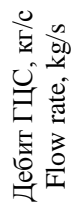 & 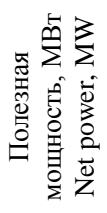 & 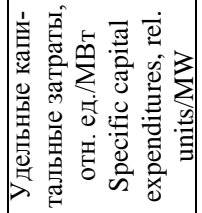 & & \\
\hline 0,1 & 24,8 & 1,3 & 1,1 & 24,7 & 1,93 & 0,76 & +48 & -32 \\
\hline 0,15 & 65,2 & 3,5 & 0,61 & 63,9 & 5,01 & 0,43 & +43 & -42 \\
\hline 0,18 & 98,6 & 5,4 & 0,5 & 95,6 & 7,7 & 0,36 & +42 & -39 \\
\hline 0,21 & 137,3 & 7,7 & 0,45 & 131,4 & 10,7 & 0,33 & +39 & -36 \\
\hline 0,24 & 179,6 & 10,2 & 0,43 & 169,2 & 13,4 & 0,32 & +31 & -34 \\
\hline 0,26 & 208,8 & 12,1 & 0,42 & 194,5 & 16,2 & 0,32 & +34 & -31 \\
\hline 0,27 & 223,4 & 13,0 & 0,43 & 206,8 & 17,3 & 0,32 & +33 & -34 \\
\hline 0,28 & 238,0 & 13,9 & 0,44 & 219,0 & 18,4 & 0,33 & +32 & -33 \\
\hline 0,29 & 252,3 & 14,9 & 0,44 & 230,8 & 19,5 & 0,34 & +31 & -29 \\
\hline 0,30 & 266,5 & 15,8 & 0,45 & 242,3 & 20,5 & 0,35 & +30 & -28 \\
\hline
\end{tabular}

Для утилизации такой низкопотенциальной энергии в настоящее время активно используются теплонасосные установки (ТНУ), где осуществляется обратный термодинамический цикл на низкокипящем рабочем веществе. ТНУ получают наибольшее применение в теплоснабжении, горячем водоснабжении административных, жилых и производственных зданий, в ряде технологических процессов. Применение ТНУ существенно повышают эффективность использования теплового потенциала отработанной ТВ, способствуя при этом и решению экологических проблем.

Таблица 2. Оптимальные значения параметров ГеоЭС в докритическом и сверхкритическом циклах Ренкина

Table 2. Optimal values of GeoES parameters in subcritical and supercritical Rankine cycles

\begin{tabular}{|c|c|c|c|c|c|c|c|c|c|}
\hline \multirow{2}{*}{ 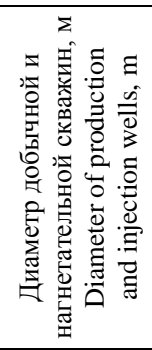 } & \multicolumn{3}{|c|}{$\begin{array}{l}\text { Докритический цикл Ренкина } \\
\text { Subcritical Rankine cycle }\end{array}$} & \multirow{2}{*}{ 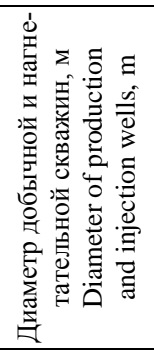 } & \multicolumn{3}{|c|}{$\begin{array}{c}\text { Сверхкритический цикл Ренкина } \\
\text { Supercritical Rankine cycle }\end{array}$} & \multirow[b]{2}{*}{ 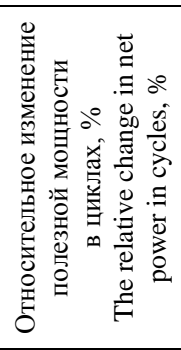 } & \multirow[b]{2}{*}{ 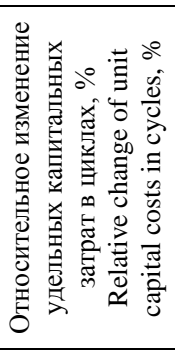 } \\
\hline & 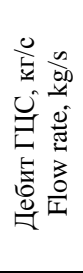 & 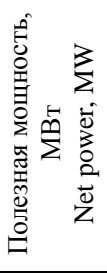 & 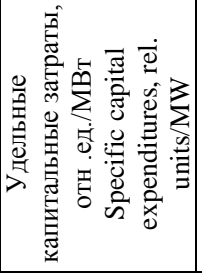 & & 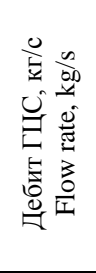 & 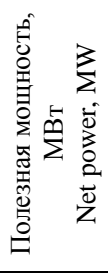 & 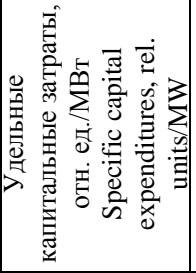 & & \\
\hline & 225,1 & 12,0 & 0,42 & & 244,5 & 1 & 0,293 & & \\
\hline $\mathrm{H}=\mathrm{d}$ & 223,8 & 12,1 & 0,42 & $\mathrm{~d}_{\mathrm{H}}=0,254$ & 243,0 & 16,7 & 0,296 & +38 & -42 \\
\hline
\end{tabular}

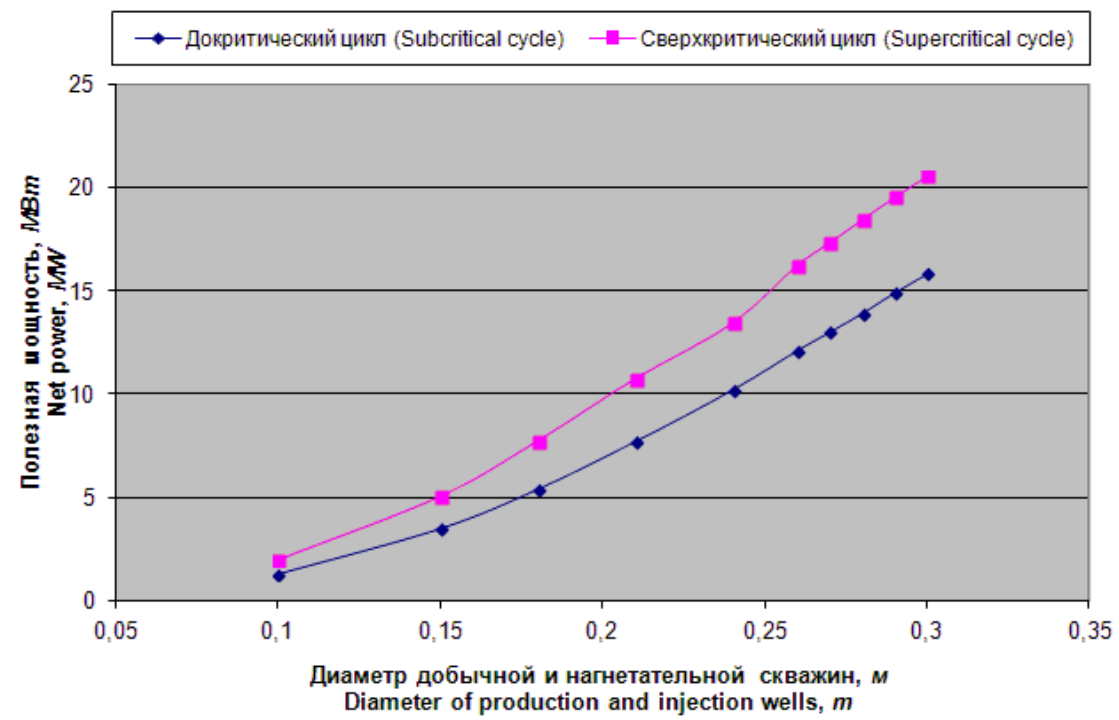

Pис. 2. Зависимость полезной мощности от диаметра добычной и нагнетательной скважин

Fig. 2. Net power dependence on the diameter of production and injection wells 


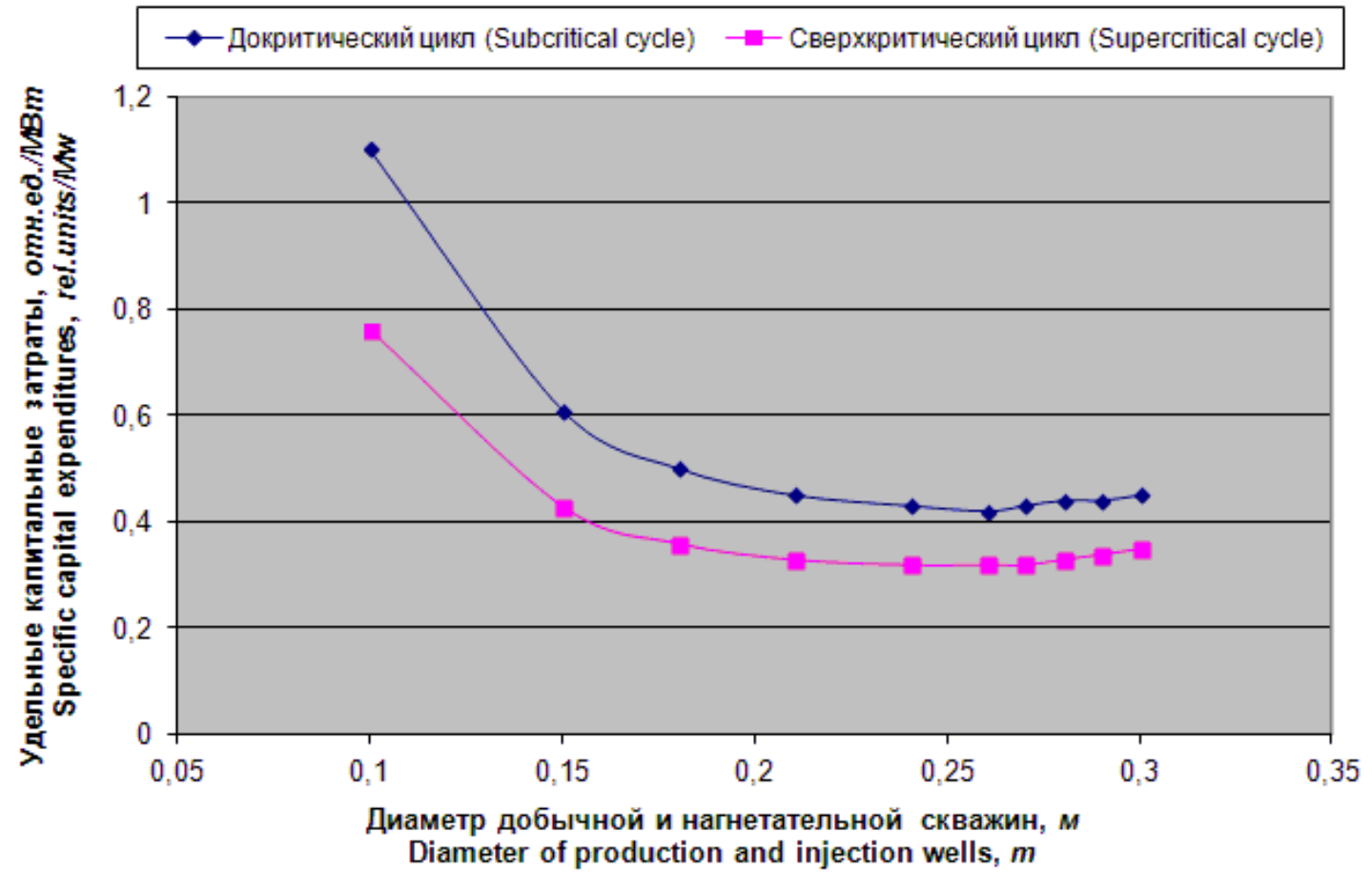

Puс. 3. Зависимость удельных капитальных затрат от диаметра добычной и нагнетательной скважин

Fig. 3. Dependence of specific capital costs on the diameter of production and injection wells

Анализ проведенных расчетов показывает существование оптимума удельных капитальных затрат (рис. 3). Оптимизация по критерию (1) дает следующие значения диаметров: $d_{\mathrm{H}}=d_{\mathrm{B}}=0,257 \mathrm{м}-$ в докритическом и $d_{\mathrm{H}}=d_{\mathrm{d}}=0,254 \mathrm{м}-$ в сверхкритическом циклах. При этом полезная мощность в сверхкритическом цикле на 34 \% выше значения в докритическом цикле, а удельные капитальные затраты на $31 \%$ меньше. Оптимизация ГЦС с разными диаметрами добычной и нагнетательной скважин позволяет улучшить эти показатели (табл. 2).

Экономическая эффективность применения ТНУ определяется капитальными затратами и соотношением цен на электроэнергию и на традиционное топливо, которое используется в котельных. Эффективность использования ТВ в ТНУ также зависит от ее конечной температуры - чем она ниже, тем выше эффективность. Для получения достаточно высоких температур конденсации рабочего вещества и повышения экономической эффективности установки, в зависимости от параметров теплоносителя в ГЦС (дебита и температуры) и конечной температуры воды, в системы теплоснабжения могут быть последовательно включены несколько (до трех) ТНУ. Расчет такой принципиальной схемы установки с двумя ТНУ приведен в [16].

Экономическая эффективность ТНУ существенна только при массовом их использовании, с расширением области применения.

Применение ТНУ для утилизации низкопотенциальной тепловой энергии отработанного теплоносителя позволяет повысить эффективность ГеоЭС с учетом дополнительно получаемой тепловой мощности.

Оценим полезную мощность, которую можно получить дополнительно, считая, что температура ТВ на входе в испаритель равна 55 и $42{ }^{\circ} \mathrm{C}$ для докритического и сверхкритического циклов, соответственно, при разных значениях температуры воды на выходе из испарителя. При этом будем считать, что с учетом возможных тепловых потерь КПД ТНУ $\eta=0,3$.

Таблица 3. Изменение суммарной мощности ГеоЭС в зависимости от температуры закачиваемой воды в докритическом иикле

Table 3. $\quad$ Change in GeoES total power depending on injected water temperature in a subcritical cycle

\begin{tabular}{|c|c|c|c|c|}
\hline \multirow[t]{2}{*}{$\begin{array}{c}\text { Температура закачивае- } \\
\text { мой обратно в пласт во- } \\
\text { ды, }{ }^{\circ} \mathrm{C} \\
\text { Temperature of water } \\
\text { injected back into the } \\
\text { reservoir, }{ }^{\circ} \mathrm{C}\end{array}$} & \multirow[t]{2}{*}{$\begin{array}{c}\text { Оптимальный де- } \\
\text { бит ГЦС, кг/c } \\
\text { Optimal flow rate, } \\
\text { kg/s }\end{array}$} & $\begin{array}{c}\text { Полезная } \\
\text { мощность } \\
\text { ГеоЭС } \\
\text { Net power }\end{array}$ & $\begin{array}{c}\text { Полезная мощность, получаемая до- } \\
\text { полнительно с учетом возможных } \\
\text { потерь }(\eta=0,3) \\
\text { Net power obtained additionally taking } \\
\text { into account possible losses }\end{array}$ & $\begin{array}{c}\text { Суммарная полез- } \\
\text { ная мощность } \\
\text { ГеоЭС } \\
\text { Total net power }\end{array}$ \\
\hline & & \multicolumn{3}{|c|}{ MBт/MW } \\
\hline 25 & 165,8 & 10,0 & 6,4 & 16,4 \\
\hline 30 & 174,1 & 10,4 & 5,6 & 16,0 \\
\hline 35 & 181,5 & 10,7 & 4,6 & 15,3 \\
\hline 40 & 188,2 & 11,1 & 3,6 & 14,7 \\
\hline 45 & 194,2 & 11,3 & 2,5 & 13,8 \\
\hline 50 & 199,6 & 11,6 & 1,3 & 12,9 \\
\hline 55 & 204,4 & 11,8 & 0,0 & 11,8 \\
\hline
\end{tabular}


Таблица 4. Изменение суммарной мощности ГеоЭС в зависимости от температуры закачиваемой воды в сверхкритическом цикле

Table 4. Change in GeoES total power depending on injected water temperature in a supercritical cycle

\begin{tabular}{|c|c|c|c|c|}
\hline \multirow[t]{2}{*}{$\begin{array}{c}\text { Температура закачивае- } \\
\text { мой обратно в пласт во- } \\
\text { ды, }{ }^{\circ} \mathrm{C} \\
\text { Temperature of water } \\
\text { injected back into the } \\
\text { reservoir, }{ }^{\circ} \mathrm{C}\end{array}$} & \multirow[t]{2}{*}{$\begin{array}{c}\text { Оптимальный де- } \\
\text { бит ГЦС, кг/c } \\
\text { Optimal flow rate, } \\
\text { kg/s }\end{array}$} & $\begin{array}{c}\text { Полезная } \\
\text { мощность } \\
\text { ГеоЭС } \\
\text { Net power }\end{array}$ & $\begin{array}{c}\text { Полезная мощность, получаемая до- } \\
\text { полнительно с учетом возможных } \\
\text { потерь }(\eta=0,3) \\
\text { Net power obtained additionally taking } \\
\text { into account possible losses }\end{array}$ & $\begin{array}{c}\text { Суммарная полез- } \\
\text { ная мощность } \\
\text { ГеоЭС } \\
\text { Total net power }\end{array}$ \\
\hline & & \multicolumn{3}{|c|}{ MBT/MW } \\
\hline 25 & 165,8 & 14,0 & 3,6 & 17,6 \\
\hline 30 & 174,1 & 14,6 & 2,6 & 17,2 \\
\hline 35 & 181,5 & 15,2 & 1,5 & 16,7 \\
\hline 42 & 190,7 & 15,8 & 0,0 & 15,8 \\
\hline
\end{tabular}

В табл. 3, 4 показана динамика изменения такой суммарной мощности ГеоЭС в зависимости от температуры закачиваемой воды в двух видах циклов.

Из данных таблиц следует, что чем выше температура закачиваемой ТВ, тем выше полезная мощность
ГеоЭС. Объясняется это уменьшением фильтрационных потерь давления в цикле ГЦС. Суммарная мощность ГеоЭС при этом меняется в обратном порядке: чем ниже температура воды на выходе из испарителя, тем выше суммарная мощность.
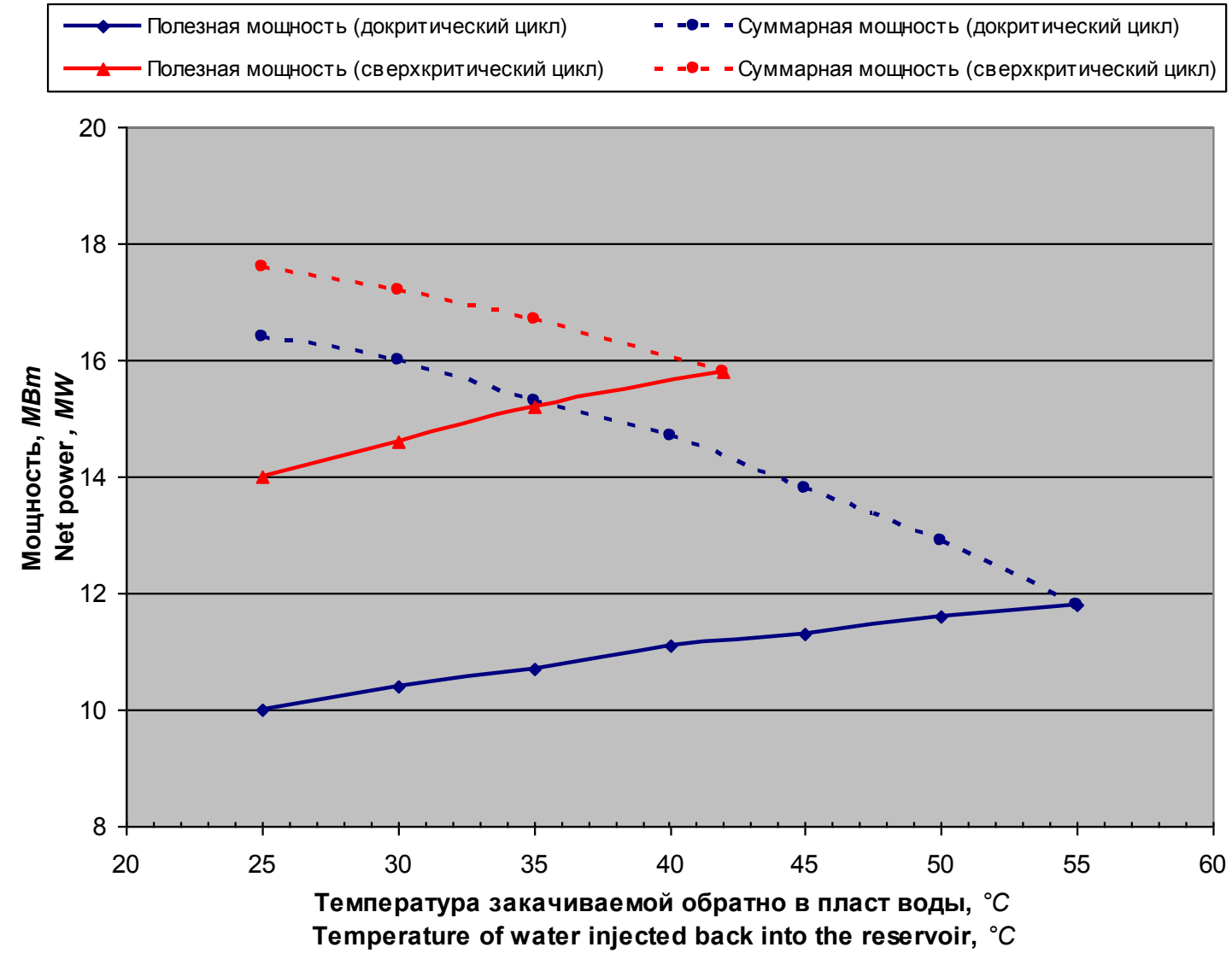

Pис. 4. Зависимость мощности от температуры закачиваемой обратно в пласт воды

Fig. 4. Dependence of power on the temperature of water injected back into the reservoir

Проведенные численные исследования и полученные данные в табл. 2 и 3 позволяют сделать следующие выводы:

- суммарная мощность, вырабатываемая турбиной, без утилизации низкопотенциальной энергии, в сверхкритическом цикле на 34 \% больше, чем в докритическом;

- суммарная мощность, вырабатываемая турбиной, с учетом утилизации низкопотенциальной энергии с применением ТНУ, в сверхкритическом цикле больше на более чем 7 \%, чем в докритическом;
- эксплуатация ГеоЭС в сверхкритическом цикле более эффективна, чем в докритическом.

Преимущества сверхкритического цикла по сравнению с докритическим очевидны. Однако использование сверхкритического цикла в ПТУ повышают и требования к турбине.

Поэтому к числу наиболее актуальных проблем повышения конкурентоспособности геотермальной энергетики относится и проблема поиска вторичных теплоносителей с более низкой критической температурой. Это позволит использовать сверхкритические 
циклы с термальными водами с более низкой температурой. Хорошую перспективу здесь имеет хладон R13 В1 (трифторбромметан) с критическими параметрами [16]: $T_{k}=66,9^{\circ} \mathrm{C}, P_{k}=3,946 \mathrm{MПа}, \rho_{k}=770 \mathrm{\kappa} \Gamma / \mathrm{M}^{3}$.

Поиск наиболее удобных рабочих агентов для геотермальных энергетических циклов путем подбора состава смеси - одно из направлений исследований Института проблем геотермии и возобновляемой энергетики - филиала ОИВТ РАН.

В заключение отметим, что создание бинарной геотермальной электростанции на Кумухском месторождении термальных вод позволит получить относительно дешевую электроэнергию мощностью до

\section{СПИСОК ЛИТЕРАТУРЫ}

1. Геотермальная энергетика: Справочно-методическое издание Г.В. Томаров, А.И. Никольский, В.Н. Семенов, А.А. Шипков под ред. П.П. Безруких. - М.: Интехэнерго-Издат, Теплоэнергетик, 2015. - 304 c.

2. Povarov O.A., Nikolski A.I., Tsimmerman S.D. Geothermal power plant at San Jacinto-Tizate // 21st Geothermal Workshop. - New Zealand, 1999. - P. 205-210.

3. Shenghua Z., Xiaokai X. Simplified model for coefficient of performance calculation of surface water source heat pump // Applied Thermal Engineering. - 2016. - V. 112. - P. 200-207.

4. Wang Y. Analysis on the practical use of open-loop surface water source heat pump systems (SWHP). - China: Chongqing University, 2011. -30 p.

5. Rybach L. Geothermal energy: sustainability and the environment // Geothermics. - 2003. - T. 32. - № 4-6. - P. 463-470.

6. Great expectations for geothermal to 2100 - messages for now / B. Goldstein, G. Hiriart, L. Gutierrez-Negrin, J. Tester, R. Bertani, C. Bromley, M. Mongillo, E. Huenges, A. Ragnarsson, H. Muraoka, V. Zui // Transactions - Geothermal Resources Council. «Geothermal Resources Council Annual Meeting 2011, Geothermal 2011». - 2011. - P. 1175-1183.

7. Петин Ю.М. Новое поколение тепловых насосов для целей теплоснабжения и эффективность их использования в России // Перспективы энергетики. - 2004. - Т. 8. - С. 27-38

8. Курбанов М.К. Геотермальные и гидроминеральные ресурсы Восточного Кавказа и Предкавказья. - М.: Наука, МАИК «Наука/Интерпериодика», 2001. - 260 с.

9. Алхасов А.Б. Технологии комплексного освоения геотермальных ресурсов Северокавказского региона // Теплоэнергетика. - 2018. - № 3. - С. 31-35.

10. Алхасов А.Б., Алхасова Д.А. Оценка эффективности создания бинарных геотермальных энергоустановок с использованием отработанных нефтяных и газовых скважин на юге России // Теплоэнергетика. - 2018. - № 2. - С. 24-32.
15 МВт, и 2-3 МВт полезной тепловой мощности на теплонасосных установках, с годовой выработкой $135 \cdot 10^{6}$ кВТ·ч электрической энергии (более 350 млн р./год) и годовой экономией замещающего топлива более 500 т.у.т. в год.

С учетом того, что геотермальные ресурсы месторождения богаты еще содержанием сырья редкоземельных металлов [16], применение технологий комплексного освоения геотермальных рассолов делают это месторождение одним из перспективных для разработки.

Таким образом, комплексное освоение Кумухского месторождения термальных вод позволит существенно улучшить экономическую структуру региона.

11. Kalina A. New thermodynamical cycles and power systems for geothermal applications // Geothermische Energie. - 2005. V. $12 / 2 / 4$. - P. 10-13.

12. Alkhasov A.B., Aliyev R.M., Magomedbekov Kh.G. Prospects of two-contour geothermal power plant construction // Renewable Energy. - 1997. - V. 10. - № 2. - P. 363-366.

13. Study of complex heat exchange with account for phase transitions in secondary contour of the geothermal power plant / A.B. Alkhasov, R.M. Aliyev, M.M. Ramazanov, G.M Abasov // Renewable Energy. - 2000. - V. 19. - № 1. - P. 155-161.

14. Алхасов А.Б., Алхасова Д.А. Комплексное использование низкопотенциальных термальных вод юга россии для тепло-, водоснабжения и решения экологических проблем // Теплоэнергетика. - 2019. - № 5. - С. 82-88.

15. Алхасов А.Б., Магомедбеков Х.Г. Перспективы строительства Геотэс на базе среднепотенциальных термальных вод // Геотермия. Геотермальная энергетика. Сб. науч. тр. ИПГ ДНЦ РАН. - Махачкала, 1994. - С. 17-35.

16. Алхасов А.Б. Геотермальная энергетика: проблемы, ресурсы, технологии. - М.: Физматлит, 2008. - 376 с

17. Джаватов Д.К., Азизов А.А. Оптимизация энергетических потерь геотермальной циркуляционной системы на обратную закачку теплоносителя. // Известия ВУЗов. СевероКавказский регион. Технические науки. - 2016. - Вып. 4. C. $51-56$.

18. Джаватов Д.К., Азизов А.А. Проблема энергетической эффективности геотермальной циркуляционной системы при различных режимах обратной закачки теплоносителя // Юг России: экология, развитие. - 2017. - Т. 12. - № 1. - С. 73-81.

19. Антониади Д.Г. Научные основы разработки нефтяных месторождений термическими методами. - М.: Недра, 1995. $315 \mathrm{c}$.

20. Джаватов Д.К. Математическое моделирование геотермальных систем и проблемы повышения их эффективности. - Махачкала: Институт проблем геотермии ДНЦ РАН, 2007. 248 c.

Поступила 04.02.2021 2.

\section{Информация об авторах}

Джаватов Д.К., доктор технических наук, профессор, заведующий кафедрой математического моделирования, эконометрики и статистики, Дагестанский государственный университет; ведущий научный сотрудник, Институт проблем геотермии и возобновляемой энергетики - филиал Объединенного института высоких температур Российской академии наук.

$\boldsymbol{A з и з о в} \boldsymbol{A} . \boldsymbol{A}$., ведущий специалист, лаборатория энергетики, Институт проблем геотермии и возобновляемой энергетики - филиал Объединенного института высоких температур Российской академии наук. 
UDC 550.36, 553.065

\title{
INCREASING THE ENERGY EFFICIENCY OF A BINARY GEO-ELECTRIC POWER STATION (ON THE EXAMPLE OF THE KUMUKH DEPOSIT)
}

\author{
Dzhavat K. Dzhavatov $1,2^{1,2}$ \\ Amir A. Azizov'1, \\ azizov_amir@mail.ru \\ 1 Dagestan State University, \\ 43 a, Gadzhiev street, Makhachkala, 367000, Russia \\ 2 Institute of Geothermy and renewable energy - branch of the Joint Institute of High Temperatures of the Russian Academy \\ of Sciences, \\ 39 a, Imam Shamil avenue, Makhachkala, 367030, Russia.
}

\begin{abstract}
The relevance of the study is caused by the need to expand the fuel and energy and mineral resources base through the development of renewable, high-potential mineralized resources of thermal water deposits. However, the exploitation of such deposits is hindered by the high degree of mineralization of natural brines. The use of binary geothermal power plants that implement the Rankine thermodynamic cycle for utilization of thermal energy allows us to solve this problem and obtain relatively cheap electrical energy. There is a need to search and evaluate methods for improving the energy efficiency of thermodynamic cycles, implemented in the development of one of the most promising deposits of thermal waters of Dagestan - Kumukh. A positive assessment of the prospects for development of geothermal resources of the field shows significant potential for improving the economic structure of the region.

Purpose: to evaluate the energy efficiency of a binary geothermal power plant, which is based on the organic Rankine cycle in subcritical and supercritical cycles and in different modes of injection of waste coolant for the Kumukh thermal water field; to show the prospects and effectiveness of integrated development of geothermal resources of the field.

Object: geothermal systems for electric power development of high potential mineralized thermal waters of the field.

The research methods are based on the use of geological exploration, hydrothermal and geochemical research data on the Kumukh thermal water deposit, methods of mathematical modeling and optimization.

Results. On the example of a specific thermal water deposit, the technological parameters of the primary circuit of the geothermal power plant were optimized, its energy efficiency was evaluated in subcritical and supercritical organic Rankine cycles with a low boiling secondary coolant. It is shown that the utilization of the low-potential energy of brines in heat pump plants can improve the efficiency of energy cycles in the field. The analysis shows that the creation of integrated technologies for development of high-potential mineralized geothermal resources of the field will significantly improve the economic structure of the region.
\end{abstract}

\section{Key words:}

Thermal water field, geothermal circulation system, double-circuit geothermal power plants,

subcritical and supercritical Rankine cycles, low-boiling working substance, optimization, low-grade heat, heat pump installations.

\section{REFERENCES}

1. Tomarov G.V., Nikolskii A.I., Semenov V.N., Shipkov A.A. Geotermalnaya energetika Spravochno-metodicheskoe izdanie [Geothermal energy: reference and methodical edition]. Ed. by P.P. Bezrukikh. Moscow, Intekhenergo-Izdat, Teploenergetik Publ., 2015. 304 p.

2. Povarov O.A., Nikolski A.I., Tsimmerman S.D. Geothermal power plant at San Jacinto-Tizate. 21 $1^{\text {st }}$ Geothermal Workshop. New Zealand, 1999. pp. 205-210.

3. Shenghua Z., Xiaokai X. Simplified model for coefficient of performance calculation of surface water source heat pump. Applied Thermal Engineering, 2016, vol. 112, pp. 200-207.

4. Wang Y. Analysis on the practical use of open-loop surface water source heat pump systems (SWHP). China, Chongqing University, 2011. $30 \mathrm{p}$.

5. Rybach L. Geothermal energy: sustainability and the environment. Geothermics, 2003, vol. 32, № 4-6, pp. 463-470.

6. Goldstein B., Hiriart G., Gutierrez-Negrin L., Tester J., Bertani R., Bromley C., Mongillo M., Huenges E., Ragnarsson A., Muraoka H., Zui V. Great expectations for geothermal to 2100 - messages for now. Transactions - Geothermal Resources Council. «Geothermal Resources Council Annual Meeting 2011, Geothermal 2011». 2011. pp. 1175-1183.

7. Petin Yu.M. Novoe pokolenie teplovykh nasosov dlya tseley teplosnabzheniya i effektivnost ikh ispolzovaniia v Rossii [New generation of heat pumps for heat supply and efficiency of their use in Russia]. Perspektivy energetiki, 2004, vol. 8, pp. 27-38.
8. Kurbanov M.K. Geotermalnye $i$ gidromineralnye resursy Vostochnogo Kavkaza $i$ Predkavkazya [Geothermal and hydromineral resources of the Eastern Caucasus and the Caucasus]. Moscow, Nauka Publ., MAIK Nauka Interperiodika Publ., 2001. $260 \mathrm{p}$.

9. Alkhasov A.B. Tekhnologii kompleksnogo osvoeniya geotermalnykh resursov Severokavkazskogo regiona [Technologies of integrated development of geothermal resources of the North Caucasus region]. Teploenergetika, 2018, no. 3, pp. 31-35

10. Alkhasov A.B., Alkhasova D.A. Otsenka effektivnosti sozdaniya binarnykh geotermalnykh energoustanovok $\mathrm{s}$ ispolzovaniem otrabotannykh neftianykh i gazovykh skvazhin na yuge Rossii [Evaluating the effect from constructing binary geothermal power units based on spent petroleum and gas boreholes in the south regions of Russia]. Teploenergetika, 2018, no. 2, pp. 24-32.

11. Kalina A. New thermodynamical cycles and power systems for geothermal applications. Geothermische Energie, 2005, vol. 12/2/4, pp. 10-13.

12. Alkhasov A.B., Aliyev R.M., Magomedbekov Kh.G. Prospects of two-contour geothermal power plant construction. Renewable Energy, 1997, vol. 10, no. 2, pp. 363-366.

13. Alkhasov A.B., Aliyev R.M., Ramazanov M.M., Abasov G.M Study of complex heat exchange with account for phase transitions in secondary contour of the geothermal power plant. Renewable Energy, 2000, vol. 19, no. 1. pp. 155-161.

14. Alkhasov A.B., Alkhasova D.A. Kompleksnoe ispolzovanie nizkopotentsialnykh termalnykh vod yuga Rossii dlya teplovodosnabzheniya i resheniya ekologicheskikh problem [Complex 
use of low-potential thermal waters of the South of Russia for heat, water supply and solution of environmental problems]. Teploenergetika, 2019, no. 5, pp. 82-88.

15. Alkhasov A.B., Magomedbekov Kh.G. Perspektivy stroitelstva Geotes na baze srednepotentsialnykh termalnykh vod [The prospect of building a Geothermal power station on the basis of mean-potential thermal waters]. Geotermiia Geotermalnaia energetika. Sb. nauch. tr. IPG DNTS RAN, 1994. pp. 17-35.

16. Alkhasov A.B. Geotermalnaya energetika: problemy, resursy, tekhnologii [Geothermal energy: problems, resources and technology]. Moscow, FIZMATLIT Publ., 2008. 376 p.

17. Dzhavatov D.K., Azizov A.A. Optimizatsiia energeticheskikh poter geotermalnoy tsirkulyatsionnoy sistemy na obratnuyu zakachku teplonositelia [Energy loss optimization in geothermal circulating system for heat-carrier reinjection]. Izvestiia VUZov Severo Kavkazskiy region. Tekhnicheskie nauki, 2016, no. 4, pp. 51-56.
18. Dzhavatov D.K., Azizov A.A. Problema energeticheskoy effektivnosti geotermalnoy tsirkuliatsionnoy sistemy pri razlichnykh rezhimakh obratnoy zakachki teplonositelya [The problem of energy efficiency of the geothermal circulation system in different modes of reinjection of the coolant]. Yug Rossii: ekologiya, razvitie, 2017, vol. 12, no. 1, pp. 73-81.

19. Antoniadi D.G. Nauchnye osnovy razrabotki neftianykh mestorozhdenii termicheskimi metodami [Scientific basis for the development of oil fields by thermal methods]. Moscow, Nedra Publ., 1995. 315 p.

20. Dzhavatov D.K. Matematicheskoe modelirovanie geotermalnykh sistem i problemy povysheniya ikh effektivnosti [Mathematical modeling of geothermal systems and the problems of increasing their efficiency]. Makhachkala, Institute of geothermal problems DSC RAS, 2007. 248 p.

Received: 4 February 2021.

\section{Information about the authors}

Dzhavat K. Dzhavatov, Dr. Sc., professor, head of department «Mathematical modeling, econometrics and statistics», Dagestan State University; leading researcher, Institute of Geothermy and renewable energy - branch of the Joint Institute of High Temperatures of the Russian Academy of Sciences.

Amir A. Azizov, leading specialist, Institute of Geothermy and renewable energy - branch of the Joint Institute of High Temperatures of the Russian Academy of Sciences. 